American J. of Engineering and Applied Sciences 2 (2): 421-427, 2009

ISSN 1941-7020

(C) 2009 Science Publications

\title{
Hot Machining of Hardened Steels with Coated Carbide Inserts
}

\author{
${ }^{1}$ M.A. Lajis, ${ }^{2}$ A.K.M.N. Amin, ${ }^{2}$ A.N.M. Karim, \\ ${ }^{2}$ H.C.D.M. Radzi and ${ }^{2}$ T.L. Ginta \\ ${ }^{1}$ Faculty of Mechanical and Manufacturing Engineering, \\ University of Tun Hussein Onn Malaysia, Malaysia \\ ${ }^{2}$ Department of Manufacturing and Material Engineering, \\ International Islamic University Malaysia, Malaysia
}

\begin{abstract}
Problem statement: The benefits of easier manufacture of hardened steel components can be substantial in terms of reduced machining costs and lead times compared to the traditional route involving machining of the annealed state followed by heat treatment, grinding/EDM and manual finishing. But machinability of hard material through conventional machining is hindered due to excessive wear of the cutting tools and differently in achieving desired quality of the machined surface. In end milling the cutting tool is not in constant operation and so undergoes a heat cycle during the intermittent cutting. This alternate heating and cooling of the inserts lead to the thermal cracks and subsequently failure of the tool. Approach: This study was conducted to investigate the effect of preheating through inductive heating mechanism in end milling (vertical milling center) of AISI D2 hardened steel (56-62 HRC) by using coated carbide tool inserts. Apart from preheating, two other machining parameters such as cutting speed and feed were varied while the depth of cut was kept constant. Results: Tool wear phenomenon and machined surface finish were found to be significantly affected by preheating temperature and other two variables. Preheating temperature of $335^{\circ} \mathrm{C}$ coupled with cutting speed of $40 \mathrm{~m} \mathrm{~min}^{-1}$, depth of cut of $1.0 \mathrm{~mm}$ and feed of $0.02 \mathrm{~mm} /$ tooth resulted in a noticeable reduction in tool wear rate leading to a maximum tool life $188.55 \mathrm{~min}$. In addition, cutting speed of $56.57 \mathrm{~m} \mathrm{~min}^{-1}$ together with feed of $0.044 \mathrm{~mm} /$ tooth and depth of cut $1.0 \mathrm{~mm}$ at which maximum VMR $\left(9500 \mathrm{~mm}^{3}\right)$ was secured provides a better surface finish with minimum surface roughness $0.25 \mu \mathrm{m}$ leaving a possibility of skipping the grinding and polishing operations for certain applications. Conclusion/Recommendation: Through the end milling of preheated AISI D2 hardened steel by using TiAlN coated carbide cutting tool it can be concluded that an overall enhanced machinability is achievable by preventing catastrophic damage of the cutting tool at higher levels of feed and cutting speed.
\end{abstract}

Key words: Hot machining, hardened steels, tool wear and surface roughness

\section{INTRODUCTION}

Hardened steel is one of the difficult-to-cut materials. During the last few years numerous studies have been conducted to improve the machinability of this kind of materials and to explore and develop new techniques to minimize machining costs while maintaining the quality requirements of the machined parts. The benefits of direct manufacture of components from hardened steel are expected to be substantial in terms of reduced machining costs and lead times compared to the traditional route of machining in the annealed state followed by heat treatment, grinding or Electrical Discharge Machining (EDM) and manual finishing ${ }^{[1]}$. Recent advances in machine tool technologies coupled with improved cutting tool inserts have opened up new opportunities for investigation in machining of hard materials especially for their bulk removal. Hot machining process which includes preheating of work-piece is gaining interest as it results in reduced shear strength creating a condition conducive to metal cutting ${ }^{[2]}$.

The technology of preheating or hot machining is not new and heat sources such as flame, electrical resistance, induction and plasma arcs were used ${ }^{[3]}$. Difficult-to-cut materials such as stainless steel, S-816 alloy, X-alloy, Inconel-X, Timken 16-25-6 and Navy Grade V, nickel chromium steel and alloy steels have

Corresponding Author: M.A. Lajis, Faculty of Mechanical and Manufacturing Engineering, University of Tun Hussein Onn Malaysia, 86400 Batu Pahat, Johor, Malaysia 
been hot machined by Tour and Fletcher ${ }^{[4]}$, Armstrong et al.$^{[5]}$, Krabacher and Merchant ${ }^{[6]}$, Schmidt and Roubik ${ }^{[7]}$ and Barrow ${ }^{[8]}$. Through analyses of their works, an important phenomenon is revealed-tool life increases to a maximum value for an optimum temperature range followed by a diminishing effect. Another important observation is the reduction in strain-hardenability and flow stress of material with increase in preheating temperature. In recent times, hot machining for cutting hard materials has been adopted by several researchers. Dumitrescu et al. ${ }^{[3]}$ applied High-Power Diode Laser (HPDL) in turning of AISI D2 tool steel. HPDL was found to inhibit saw tooth chip formation, suppress chatter, deter catastrophic tool fracture and bring about substantial reduction in tool wear and cutting forces leaving minimal effect on the integrity of the machined surface. It is, therefore, less likely to experience very adverse effects on the machined surface due to preheating.

Maity and Swain ${ }^{[2]}$ adopted plasma assisted heating in turning of high manganese steel using carbide tool and concluded that the effect of increased workpiece temperature would have a very significant effect on tool life. Ozler et al. ${ }^{[9]}$ integrated plasma gas heating in turning of austenitic manganese steel and noticed that tool life would increase with increase in heating temperatures. He concluded that the decrease in the strength of the workpiece is induced by the influence of heat most of which is transferred to the chip-tool interface.

Preheating of workpiece by induction heating has been recently reported to enhance the machinability of other materials. Amin et al. ${ }^{[10]}$ carried out preheated induction heating in end milling of AISI D2 hardened steel using PCBN inserts and observed that machining of preheated material led to surface roughness values well below $0.4 \mu \mathrm{m}$, with which grinding and polishing operations could be avoided for certain applications. Preheated machining has been found to reduce the amplitude of the lower frequency mode of chatter by almost 4.5 times at the cutting speed of $50 \mathrm{~m} \mathrm{~min}^{-1}$. It was also established by several other earlier studies $^{[11,12]}$ that preheating had great potential in lowering chatter.

It is apparent that preheating enhances the ductility of the material for easier chip formation and flow over the rake surface of the tool. This easier formation and flow of chip is expected to improve the tool life and surface finish of the machined components. Earlier study conducted by Amin et al. ${ }^{[10]}$ was restricted with a lower range of preheating temperature $\left(100-150^{\circ} \mathrm{C}\right)$ to avoid a situation where preheating might lead to softening of the hardened work-piece. The current study was initiated to investigate the scope of preheating the work material to a higher level of temperature closer to re-crystallization temperature. Thus for AISI D2 hardened steel work material preheating was performed to a temperature range from $250-450^{\circ} \mathrm{C}$ by using induction heating approach prior to end milling operation.

\section{MATERIALS AND METHOD}

The machining operation was carried out on a Vertical Machining Center (VMC) using a $40 \mathrm{~mm}$ diameter tool holder fitted with Sandvik 1030 PVD coated carbide inserts. End milling operation was performed under dry cutting condition with a $5 \mathrm{~mm}$ constant radial depth of cut. Experimental set-up for hot machining of AISI D2 hardened steel is shown in Fig. 1. One edge out of the four cutting edges of a tool insert was used for each set of experimental conditions. Thus machining was initiated with a new sharp edge of an insert and continued for a $100 \mathrm{~mm}$ pass of cut followed by checking of the flank wear. This procedure was continued until the flank wear of the tool reached a magnitude of $0.30 \mathrm{~mm}$. Olympus tool maker microscope was used to measure the flank wear with a magnification of $(20 \mathrm{x})$. The $0.30 \mathrm{~mm}$ flank wear criterion was adopted in accordance with the ISO standard (ISO standard 8688-2, 1989 for tool life testing of end milling).

Selection of machining conditions: The cutting conditions were selected primarily by considering the recommendations made by cutting tool manufacturer (Sandvik tools) and the knowledge on practices gathered through contemporary literatures on hard machining. Selected three main parameters: Cutting speed, feed and preheating temperature were changed while the axial depth of cut, d was kept constant at 1 $\mathrm{mm}$. The ranges of parameters used for experimentation were: Feed, f: 0.02-0.044 $\mathrm{mm}$ tooth $^{-1}$; cutting speed,

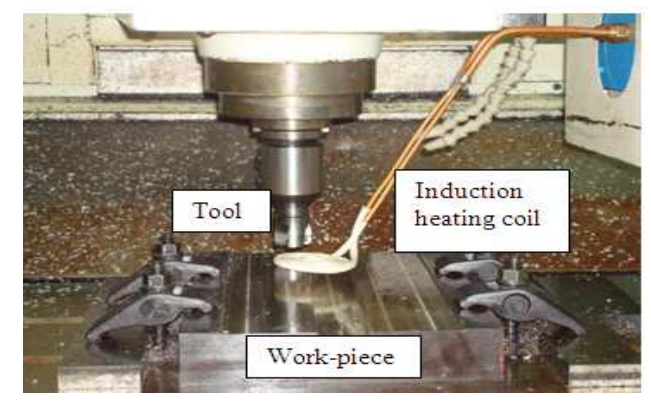

Fig. 1: Experimental set-up of hot machining 


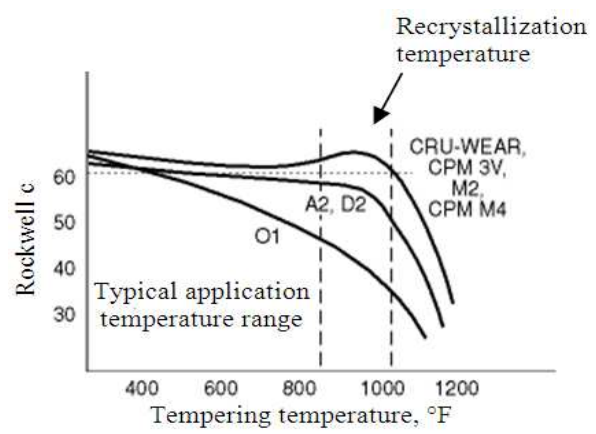

Fig. 2: Hardness of D2 material among others as varied with tempering temperature

Table 1: Experimental condition with corresponding tool life and surface roughness

\begin{tabular}{lllrrc}
\hline \multirow{2}{*}{$\begin{array}{l}\text { Experimental } \\
\text { No. }\end{array}$} & $\begin{array}{l}\text { Cutting speed } \\
\left.\mathrm{V}(\mathrm{m} \mathrm{min})^{-1}\right)\end{array}$ & $\begin{array}{l}\text { Feed }(\mathrm{mm} \\
\left.\text { tooth }^{-1}\right)\end{array}$ & $\begin{array}{l}\text { Preheating } \\
\text { temperature }\end{array}$ & $\begin{array}{l}\text { Tool life } \\
\mathrm{TL}(\mathrm{min})\end{array}$ & $\begin{array}{l}\text { Surface } \\
\text { roughness } \\
\mathrm{Ra}(\mu \mathrm{m})\end{array}$ \\
\hline 1 & 40.00 & 0.020 & 30 & 157.13 & 0.35 \\
2 & 40.00 & 0.020 & 335 & 188.55 & 0.23 \\
3 & 40.00 & 0.044 & 30 & 64.28 & 0.43 \\
4 & 40.00 & 0.044 & 335 & 121.41 & 0.27 \\
5 & 40.00 & 0.100 & 30 & 25.14 & 0.47 \\
6 & 40.00 & 0.100 & 335 & 31.43 & 0.30 \\
7 & 56.57 & 0.020 & 30 & 55.55 & 0.31 \\
8 & 56.57 & 0.020 & 335 & 99.99 & 0.20 \\
9 & 56.57 & 0.044 & 33 & 28.79 & 0.40 \\
10 & 56.57 & 0.044 & 335 & 95.95 & 0.25 \\
11 & 56.57 & 0.100 & 30 & 7.33 & 0.49 \\
12 & 56.57 & 01.00 & 335 & 18.82 & 0.27 \\
13 & 80.00 & 0.020 & 30 & 31.43 & 0.23 \\
14 & 80.00 & 0.020 & 335 & 54.99 & 0.11 \\
15 & 80.00 & 0.100 & 30 & 1.73 & 0.37 \\
16 & 80.00 & 0.044 & 335 & 25.35 & 0.22 \\
17 & 80.00 & 0.100 & 30 & 1.73 & 0.75 \\
18 & 80.00 & 0.100 & 335 & 3.93 & 0.41 \\
19 & 56.57 & 0.044 & 250 & 85.86 & 0.34 \\
20 & 56.57 & 0.044 & 450 & 119.43 & 0.19 \\
\hline
\end{tabular}

$\mathrm{V}: 40-80 \mathrm{~m} \mathrm{~min}^{-1}$; and preheating temperature, $\theta: 30$ $450^{\circ} \mathrm{C}$. Re-crystallization temperature of work-piece material (AISI D2) ${ }^{[13]}$ as showed in Fig. 2 was taken into consideration to limit the maximum level of preheating temperature.

Experimental conditions were set by choosing the discrete values lying within the above mentioned ranges of the three selected parameters. Table 1 shows 20 sets of experimental conditions corresponding to which the machining operations were conducted. Data on tool life and surface roughness values of the machined surface are also included.

Process of preheating: An induction heating device having a capacity of $25 \mathrm{kVA}$ was used for preheating the work-piece. As shown in Fig. 1 the induction heating coil was mounted just ahead and in close proximity of the
Table 2: Chemical composition and hardness of AISI D2 Chemical composition of the work material

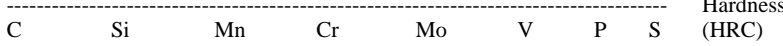
\begin{tabular}{lllllllll}
$\mathrm{C}$ & $\mathrm{Si}$ & $\mathrm{Mn}$ & $\mathrm{Cr}$ & $\mathrm{Mo}$ & $\mathrm{V}$ & $\mathrm{P}$ & $\mathrm{S}$ & (HRC) \\
\hline $1.50-1.60$ & $0.10-0.40$ & $0.15-0.45$ & $11.0-12.0$ & $0.60-0.80$ & $0.9-1.1$ & 0.03 & 0.03 & $56-62$
\end{tabular}

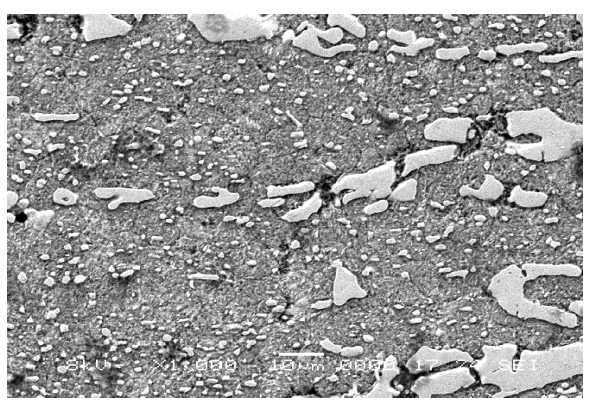

Fig. 3: Microstructure of the AISI D2 after heat treatment

cutting tool. This close position of the heating coil with the tool is expected not to allow enough time to transfer the heat substantially from the surface of the workpiece prior to machining. The temperature on the surface of the work material was measured with the help of an infrared pyrometer (Omega, OS-651 having the ability to measure temperature ranging between -29$1093^{\circ} \mathrm{C}$ with an accuracy of $\pm 1 \%$ ). Work-piece preheating temperature was calibrated by measuring for a particular current value and feed rate of the machine table as used during actual machining. So to obtain a desired preheating temperature of work-piece surface during machining operation a particular rated current value was set for a specific feed rate of VMC system.

Work and cutting tool materials: The work material as received from supplier was in the form of a block hardened by oil quenching and tempered to a hardness range of $56-62 \mathrm{HRC}$ having $300 \times 250 \times 100 \mathrm{~mm}$ in dimension. Hardness of work material was verified and found to comply with the supplier's specifications as showed in Table 2.

As mentioned earlier the material used for machining operation was AISI D2, the microstructure (1000× magnification) of which is shown in Fig. 3 .

The end milling tool holder was a Sandvik Coromill 390 Endmill: R390-020B20-11L employing indexable inserts having code: Sandvik 1030 Coromill 290 R290-12T308E-PL. The TiAlN coated carbide inserts having four sided cutting edges were used as received from the supplier. Figure 4 shows a schematic diagram indicating the geometry of tool insert (Sandvik 1030) as coated through PVD method by manufacturer with relevant dimensions in Table 3. 


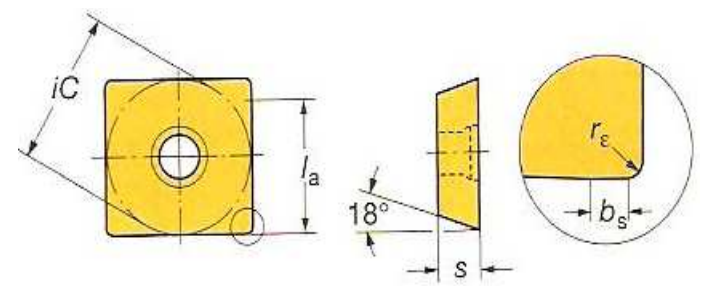

Fig. 4: Geometry of TiAlN Coated Carbide tool insert (Sandvik 1030)

Table 3: Dimensions of tool insert (Sandvik 1030)

\begin{tabular}{|c|c|c|c|c|c|}
\hline \multirow[b]{2}{*}{$\begin{array}{l}\text { Maximum depth } \\
\text { of cut, }\end{array}$} & \multicolumn{5}{|c|}{ Dimension are in $\mathrm{mm}$} \\
\hline & $\mathrm{d}(\mathrm{mm})$ & $\mathrm{iC}$ & $1_{\mathrm{a}}$ & $\mathrm{S}$ & $b_{\mathrm{s}}$ \\
\hline 6 & 13.29 & 6.4 & 3.97 & 1.46 & $0.9-1.1$ \\
\hline
\end{tabular}

\section{RESULTS}

Tool wear and tool life: Maintaining tool wear to a minimum level is a great challenge in machining of hardened steel. Experiments in this study have demonstrated that tool wear in end milling of AISI D2 hardened steel without preheating could be quite severe and catastrophic. As shown in Fig. 5, the flank wear exceeded the limiting value of $0.3 \mathrm{~mm}$ in less than 7.33 min of machining time after cutting a length of $330 \mathrm{~mm}$ with a cutting speed of $56.57 \mathrm{~m} \mathrm{~min}^{-1}$, feed of 0.1 $\mathrm{mm} /$ tooth and depth of cut of $1.0 \mathrm{~mm}$. In this case the tip of cutting tool insert ended up with breakage.

However, under the same cutting speed but with a lower feed ( $\mathrm{f}=0.044 \mathrm{~mm} \operatorname{tooth}^{-1}$ ) the situation improved and the tool wear reached the limiting value of $0.30 \mathrm{~mm}$ after about $35 \mathrm{~min}$ of machining (Fig. 6). Preheating of work-piece has been found to further increase the tool life by reducing the tool wear rate quite significantly.

Progression of tool wear as a function of machining time with different preheating temperatures is shown in Fig. 6. Enhanced tool life was obtained with the increase in preheating temperature. The longest tool life was achieved at $450^{\circ} \mathrm{C}$ preheating temperature. As shown in Fig. 2, AISI D2 hardened steel re-crystallizes at a temperature ranging from 850$1050^{\circ} \mathrm{F}$ which is equivalent to $455-565^{\circ} \mathrm{C}$. This is why the maximum preheating temperature applied in this experiment was set at $450^{\circ} \mathrm{C}$ which is lower than the recrystallization temperature. A preheating temperature higher than $450^{\circ} \mathrm{C}$ could pose an undesirable effect on the work material especially in the context of hardness.

Tool life was estimated from the plot in Fig. 6 for different preheated temperature and the values are $28.79,85.86,95.95$ and $119.43 \mathrm{~min}$ respectively for preheating temperature of $30^{\circ} \mathrm{C}$ (room temperature),

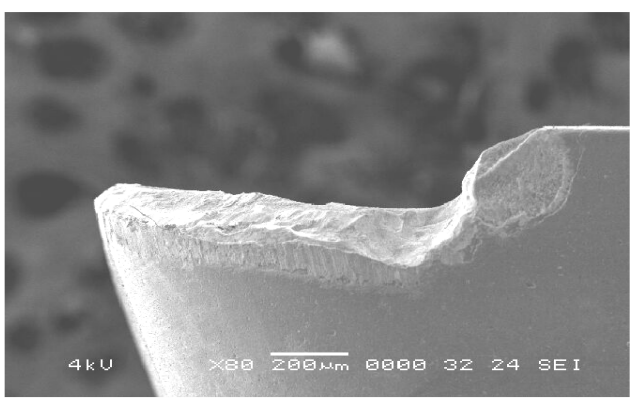

Fig. 5: Tool wear observed after machining without preheating a cutting length of $300 \mathrm{~mm}$ $\left[\mathrm{V}=56.57 \mathrm{~m} \min ^{-1}, \quad \mathrm{f}=0.1 \mathrm{~mm}\right.$ tooth $^{-1}$, $\mathrm{d}=1.00 \mathrm{~mm}]$

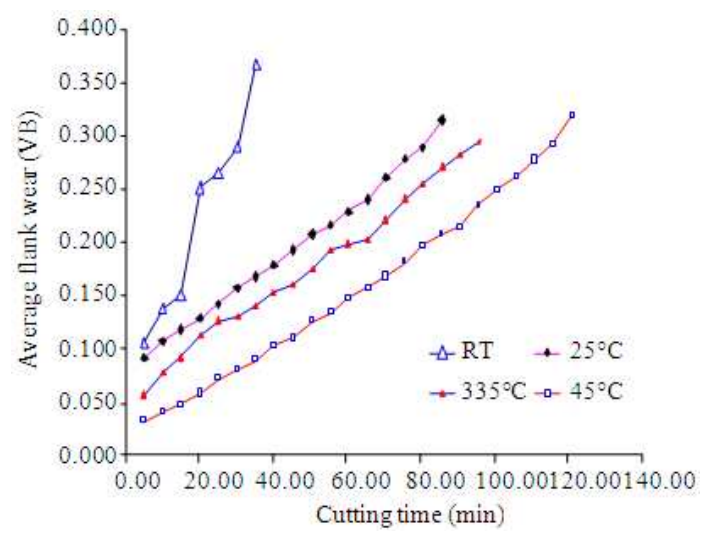

Fig. 6: Influence of work-piece preheating temperature on flank wear with different cutting time $\left[\mathrm{V}=56.57 \mathrm{~m} \mathrm{~min}{ }^{-1}, \mathrm{f}=0.044 \mathrm{~mm} \mathrm{tooth}^{-1}\right.$, $\mathrm{d}=1.0 \mathrm{~mm}]$

250,335 and $450^{\circ} \mathrm{C}$. With these data a simple linear regression has been performed to correlate the tool life $(\mathrm{TL}, \mathrm{min})$ as a function of work-piece preheating temperature $\left(\theta^{\circ} \mathrm{C}\right)$. The developed linear equation exhibits a positive trend which is as follows:

$$
\mathrm{TL}=25.22+0.215 \theta
$$

The positive coefficient of $\theta$ indicates that with the increase in preheating temperature the tool life increases. The coefficient of correlation $(r)$ was found to be 0.992 leading to a coefficient of determination $\left(r^{2}\right)$ of 0.99 . The significance of $r^{2}$ value of 0.998 is that $99 \%$ of the tool life variation can be explained by the regression equation. However, this relationship should be valid under the preheating temperature range of 30$450^{\circ} \mathrm{C}$ and other machining conditions used in conducting the experiments. 


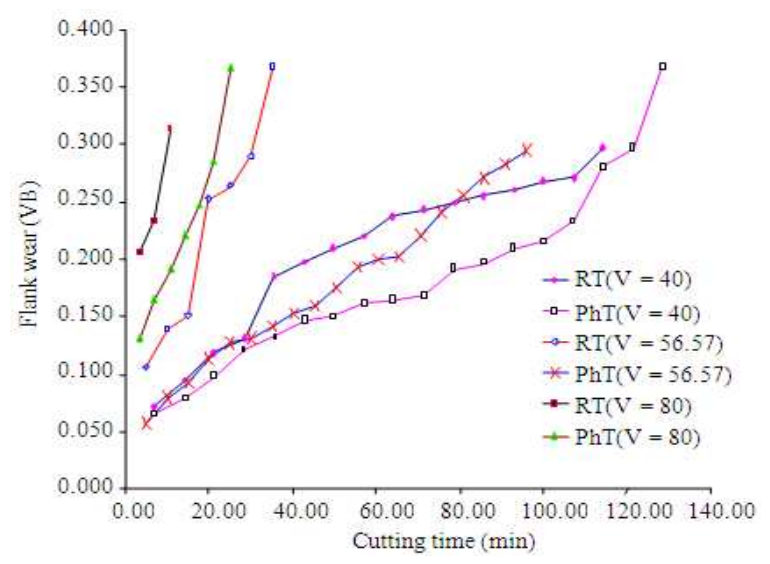

Fig. 7: Flank wear influenced by preheating temperature and cutting speed with different cutting time $\left[\mathrm{f}=0.044 \mathrm{~mm}\right.$ tooth $\left.^{-1}, \mathrm{~d}=1.0 \mathrm{~mm}\right]$

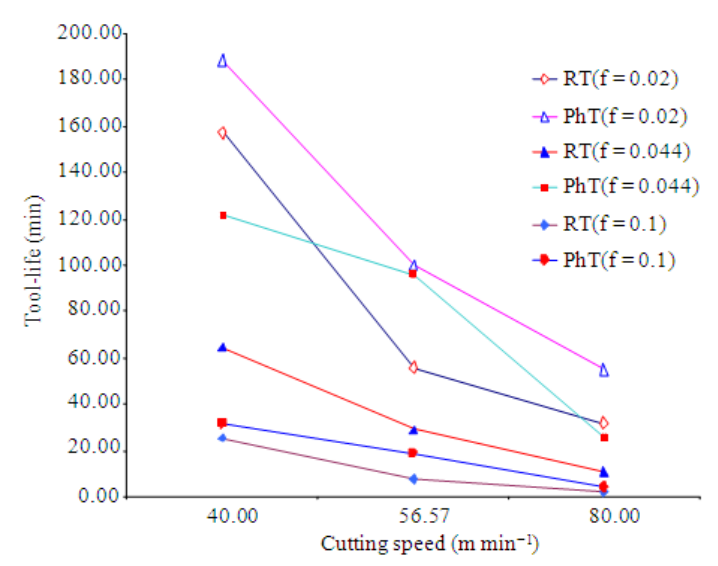

Fig. 8: Tool life affected by feed at different cutting speeds and preheating temperature

Figure 7 shows 6 curves indicating the tool wear which correspond to the three cutting speeds $(40,56.57$ and $80 \mathrm{~m} \mathrm{~min}^{-1}$ ) and two temperatures (room temperature, $30^{\circ} \mathrm{C}$ and a preheating temperature of $335^{\circ} \mathrm{C}$ ). It is clearly evident that tool life is enhanced with preheating for the same cutting speed. But the influence of preheating temperature on tool life is found to be high at cutting speed of $56.57 \mathrm{~m} \mathrm{~min}^{-1}$ and it becomes less prominent with the highest cutting speed $\left(80 \mathrm{~m} \mathrm{~min}^{-1}\right)$.

As shown in Fig. 8, the higher the feed the lower is the tool life. These results may be explained in terms of higher stress encountered by the tool due to higher feed. However, the metal removed per tool life would be an appropriate criterion for assessing machinability.

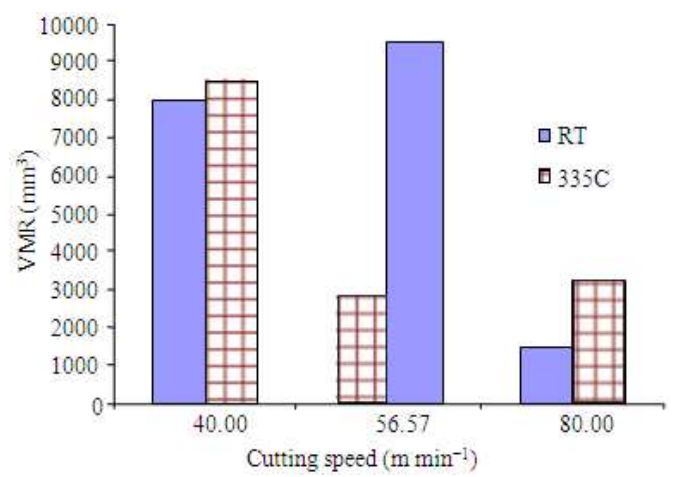

Fig. 9: Volume of material removed per tool life influenced by preheating temperature and cutting speed. [ $\mathrm{f}=0.044 \mathrm{~mm}$ tooth $^{-1}, \mathrm{~d}=1.0 \mathrm{~mm}$ ]

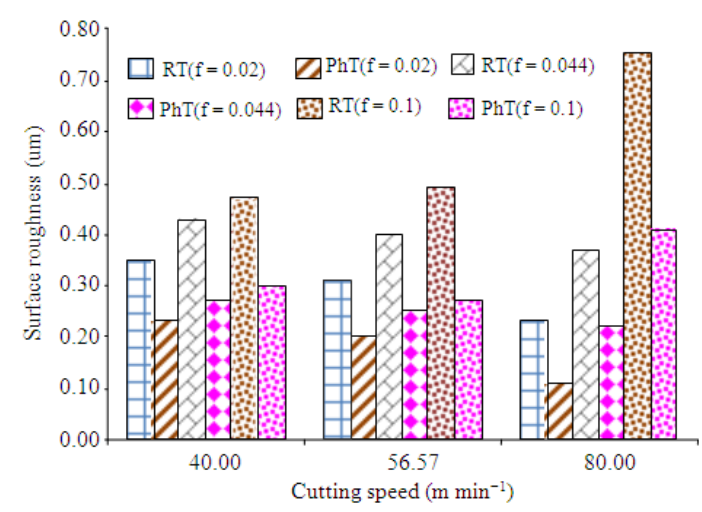

Fig. 10: Machined surface roughness as influenced by cutting speed and preheating temperature [RT and $\left.\mathrm{PhT}=335^{\circ} \mathrm{C}\right]$

Figure 9 shows the Volume of Metal Removed (VMR) per tool life for different cutting conditions. In this case the feed was kept constant with $0.044 \mathrm{~mm}$ tooth $^{-1}$. Preheating temperature was $335^{\circ} \mathrm{C}$ and cutting speed was varied into three levels. It is apparent that compared to room temperature, preheating led to higher VMR per tool life irrespective of any cutting speed. However, at lower cutting speed VMR increase due to preheating is marginal while at medium speed $\left(56.57 \mathrm{~m} \mathrm{~min}^{-1}\right)$ it is maximum with a decline at the higher cutting speed.

Machined surface roughness: Average of two surface roughness values, Ra values of the machined surface under different cutting conditions are plotted in Fig. 10. Irrespective of whether machining was performed at room temperature or with preheating, for a constant cutting speed surface roughness value increased with increasing feed. But with increase in cutting speed there is no such trend. 


\section{DISCUSSION}

Tool wear followed by machining under room temperature was very intense with severe abrasive and notch wear of the cutting edge as evident in Fig. 11a. These phenomena can be considered as the result of carbides constituents (as shown in Fig. 3 responsible for the enhanced abrasive wear resistance of D2 tool steel.

Abrasive wear is much likely to be a significant wear process with coated carbides due to the high hardness of tungsten carbide. According to Becze et al. ${ }^{[14]}$, the carbide phase thus hampers the machinability of hardened D2 both in terms of increasing the flow stress of the material and inflicting severe abrasive wear on the tool. Figure $11 \mathrm{~b}$ of $250^{\circ} \mathrm{C}$ preheated machining shows slightly similar trend where the abrasive wear was not so severe compared to room temperature machining but there is a higher scale of notch wear. This may be due to the insufficient temperature to induce appreciable softening of the work material.

Preheating of work material at 335 and $450^{\circ} \mathrm{C}$ led to occurrence of uniform average wear on the cutting edges as shown in Fig. 11c and d. However, preheated machining with $450^{\circ} \mathrm{C}$ presents a smooth type of wear with features characterizing the diffusion wear process which is temperature dependent.

Diffusion wear is a mechanism where a constituent of a workpiece material diffuses into or forms a solid solution with the tool or chip material. Hence, an EDAX analysis, shown in Fig. 12, was performed to investigate the diffusion characteristics of the workpiece into the cutting tool. The analysis shows the significant existence of Ferum $(60.88 \% \mathrm{Fe})$, carbon $(25.3 \% \mathrm{C})$ and chromium $(4.9 \% \mathrm{Cr})$ on the tool surface as shown in Fig. $12 b$.

As shown in Fig. 10 above, at lower level of feed $\left(0.02\right.$ and $0.044 \mathrm{~mm}$ tooth $\left.^{-1}\right)$ surface finish had improved having lower roughness values as the cutting speed was increased. But at higher feed ( $\mathrm{f}=1.0 \mathrm{~mm}$ tooth $^{-1}$ ) surface finish had generally deteriorated having higher roughness values as the cutting speed was increased. It is observed from the plot that with preheating of work material surface roughness values are close to or below $0.3 \mu \mathrm{m}$ at any combination of cutting speed and feed. In case of the cutting speed of $56.57 \mathrm{~m} \mathrm{~min}^{-1}$ at which maximum VMR was secured, even a better surface finish is possible to be maintained with lower range of roughness values. Thus with preheating it would be possible to skip the grinding and even polishing operation in preparing die and mold for certain applications.

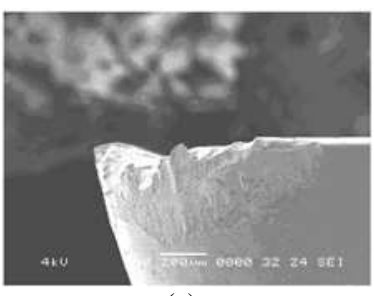

(a)

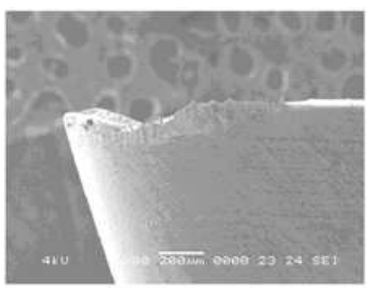

(c)

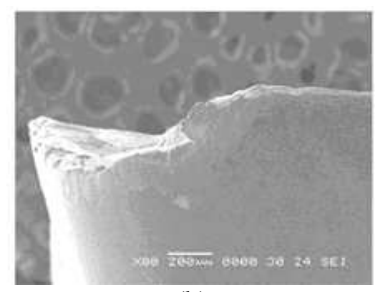

(b)

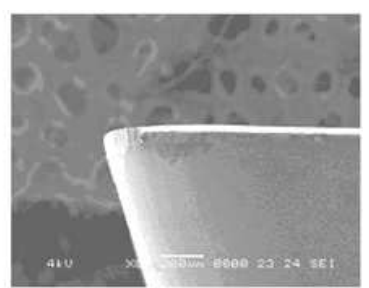

(d)
Fig. 11: SEM photographs of the worn tools at the end of machining tests: (a): At room-temperature; (b): At $250^{\circ} \mathrm{C}$; (c): At $335^{\circ} \mathrm{C}$; (d): At $450^{\circ} \mathrm{C}$, $\left[\mathrm{v}=56.57 \mathrm{~m} \mathrm{~min}^{-1}, \mathrm{f}=0.044 \mathrm{~mm} \mathrm{tooth}^{-1}\right.$, $\mathrm{d}=1.00 \mathrm{~mm}]$
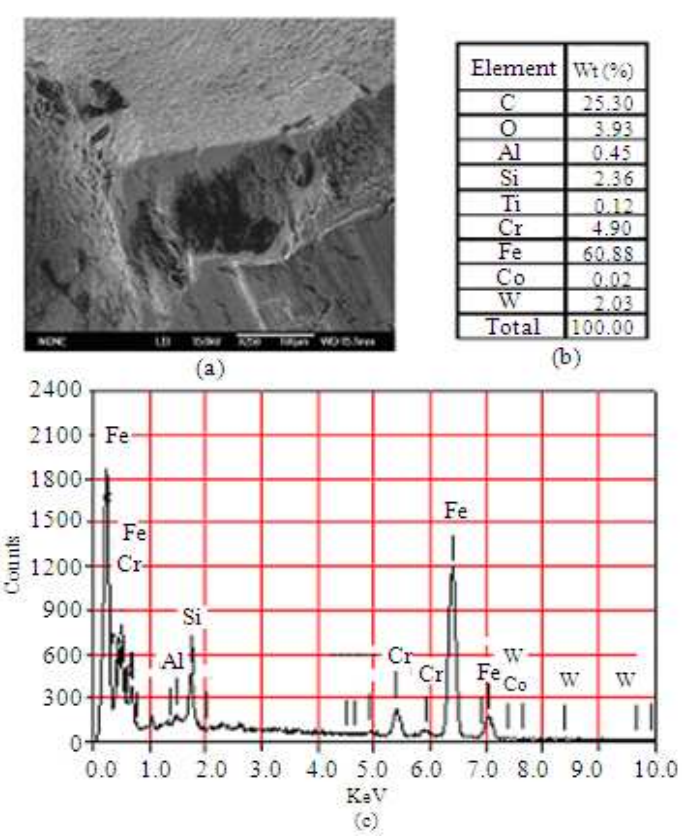

Fig. 12: SEM and EDAX analysis of coated carbide for $450^{\circ} \mathrm{C} \mathrm{PhT} \mathrm{machining} \mathrm{[v}=56.57 \mathrm{~m} \mathrm{~min}^{-1}$, $\left.\mathrm{f}=0.044 \mathrm{~mm}_{\text {tooth }}{ }^{-1}, \mathrm{~d}=1.00 \mathrm{~mm}\right]$

\section{CONCLUSION}

Through the end milling of preheated AISI D2 hardened steel by using TiAlN coated carbide cutting 
tool it can be concluded that an overall enhanced machinability is achievable by preventing catastrophic damage of the cutting tool at higher levels of feed and cutting speed. To be specific the following conclusions can be drawn from the conducted experiments:

- $\quad$ Preheating of the AISI D2 work material enhances the tool life by slowing down the tool wear rate and preventing catastrophic tool failure

- Higher cutting speed was found to diminish the positive effect of preheating. A range of 40-60 m $\min ^{-1}$ for cutting is expected to be suitable with a preheating temperature of $336^{\circ} \mathrm{C}$. Cutting speed of $56.57 \mathrm{~m} \mathrm{~min}^{-1}$ at which maximum VMR was secured, provides a better surface finish with roughness values lower than $0.3 \mu \mathrm{m}$

- Thus with preheating it would be possible to skip the grinding and even polishing operation in preparing dies and molds for certain applications

- A linear regression equation for tool life has been established for a range of preheating temperature $\left(30-450^{\circ} \mathrm{C}\right)$. This equation would be useful to predict the tool life for a particular preheating temperature lying within the range

- However, incorporation of preheating mechanism obviously incurs costs, a detailed study is necessary to check whether the costs are offset by the benefits obtained through the process

\section{ACKNOWLEDGEMENT}

This study was conducted under the purview of the e-science project (03-01-08-SF0003) entitled "Enhancement of Machinability of Hardened Steel in End Milling Using Advanced Cutting Methods and Tools", funded by the Ministry of Science, Technology and Innovation of Malaysia (MOSTI). The authors gratefully acknowledge the financial support.

\section{REFERENCES}

1. Koshy, P., R.C. Dewes and D.K. Aspinwall, 2002. High speed end milling of hardened AISI D2 tool steel ( 58 HRC). J. Mater. Process. Technol., 127: 266-273. DOI: 10.1016/S09240136(02)00155-3

2. Maity, K.P. and P.K. Swain, 2007. An experimental investigation of hot-machining to predict tool life. J. Mater. Process. Technol., 198: 344-349.

DOI: 10.1016/j.jmatprotec.2007.07018
3. Dumitrescu, P., P. Koshy, J. Stenekes and M.A. Elbestawi, 2006. High-power diode laser assisted hard turning of AISI D2 tool steel, 2006. Int. J. Mach. Tools Manufact., 46: 2009-2016. DOI: 10.1016/j.ijmachtools.2006.01.005

4. Tour, S. and L.S. Fletcher, 1978. Hot spot machining. IronAge, 164-170.

5. Armastrong, E.T., A.S. Closer and E.F. Kate, 1951. Machining of heated metals. ASME., 35: 73.

6. Krabacher, E.J. and M.E. Merchant, 1951. Basic factors in hot machining of metals. Trans. ASME., 73: 761.

7. Schmidt, A.O. and H.R. Roubik, 1949. Milling hot work piece. Eng. Dig., 10: 101-105.

8. Barrow, G., 1966. Machining at high strength metals at elevated temperature using electrical current heating. Ann. CIRP., 14: 145-151. http://www.cirp.net/index.php?option=com_cirppu bli\&Itemid=130\&type $=$ publication $\&$ year $=1966$

9. Ozler, L., A. Inan and C. Ozel, 2001. Theoretical and experimental determination of tool life in hot machining of austenitic manganese steel. Int. J. Mach. Tools Manufact., 41: 163-172. DOI: 10.1016/S0890-6955(00)00077-8

10. Amin, A.K.M.N., S.B. Dolah, M.B. Mahmud and M.A. Lajis, 2008. Effects of workpiece preheating on surface roughness, chatter and tool performance during end milling of hardened steel D2. J. Mater. Process. Technol., 201: 466-470. DOI: 10.1016/j.jmatprotec.2007.11.304

11. Amin, A.K.M.N. and M.M. Abdelgadir, 2003. The effect of preheating of work material on chatter during end milling of medium carbon steel performed on a Vertical Machining Center (VMC), ASME J. Manufact. Sci. Eng., 125: 674-680. DOI: 10.11155/1.1596557.

12. Amin, A.K.M.N., I. Abraham and N. Khairussima, 2007. Influence of preheating on performance of circular carbide inserts in end milling of carbon steel. J. Mater. Process. Technol., 185: 97-105. http://cat.inist.fr/?aModele $=$ afficheN\&cpsidt $=1857$ 5769

13. Reed-Hill Robert, E., 1991. Physical Metallurgy Principles. 3rd Edn., PWS Publishing, Boston, ISBN: 0534921736, pp: 994.

14. Becze, C.E., M.J. Worswick and M.A. Elbestawi, 2001. High strain rate shear evaluation and characterization of AISI D2 tool steel in its hardened state. Machin. Sci. Technol., 5: 131-149. DOI: 10.1081/MST-100103181 